\title{
TEXTOS Y CONTEXTOS ICONOGRÁFICOS DE HORMIGUERO, CAMPECHE: SU EDIFICIO II DURANTE LA FASE XCOCOM
}

\author{
Arturo Pascual Soto
}

Durante el ocaso de su fase Xcocom (ca. 830-970 dG) (cf. J. Ball, 1977) Hormiguero, uno de los asentamientos más australes en la región de Río Bec, parece estar constituido por un grupo residual de pobladores. Los cuartos de los para entonces abandonados edificios sirvieron como improvisadas moradas y, en algún caso, se prepararon al descuido pequeñas plataformas habitacionales. Hormiguero, hoy en la selva de Campeche, apenas se mantenía ocupado.

En el otoño pasado me tocó abrir la excavación arqueológica en dos de estas tardías plataformas habitacionales de Hormiguero. * Ambas configuraron, por un breve espacio de tiempo, una reducida unidad habitacional (UH01). Su entorno inmediato fueron los varios edificios que, construidos en algún momento anterior, probablemente presentaban ya un aspecto ruinoso; entre tanto, el quehacer cotidiano se renovaba en esta pequeña unidad habitacional de los últimos años de la fase Xcocom.

En ese tiempo y al poniente, no lejos de allí, alguien debió habitar los abandonados cuartos del Edificio II. Las vecinas plataformas de aquella pequeña unidad habitacional quizá ya se encontraban ocupadas y tan sólo las cerámicas estriadas, pertenecientes a una ya larga tradición doméstica, permanecían inmutables en una región donde todo había cambiado.

Todo aquel transtorno que la tradición Río Bec sufrió en Hormiguero hubo de iniciarse en otro tiempo, en varios lugares de la región, y en todos ellos se encuentra asociado con artefactos cerámicos de tipo Pizarra (cf. L. C. Messenger Jr., 1975 y J. Ball, 1977). En Hormiguero la arqueología del Edificio II, testigo de aquellos años, dispone de algunos datos vinculados con los eventos ocurridos en la fase Xcocom.

Mientras transcurría la fase Sabucan (ca. 450-600/630 dC), o bien durante los inicios de Bejuco (ca. 600/630-730/750 dC) (cf. J. Ball,

\footnotetext{
* Dicha excavación formó parte de las investigaciones arqueológicas que el Centro Regional de Campeche (INAH), a cargo del arquitecto José Enxique Ortiz Lanz, lleva a cabo en esta localidad atqueológica de la región de Río Bec bajo la dirección del doctor Román Piña Chan y de la que es responsable Ricardo Bueno Cano.
} 
1977), aparece un edificio (Estructura II -sub) carente de Ias torres masivas características de la posterior arquitectura Río Bec (figura 1) (cf. P. Gendrop, 1983). Aquella construcción de dos crujías paralelas sobre una modesta plataforma fue acortada quizá en algún momento de la siguiente fase Chintok (ca. 730/750-830 dC) (cf. J. Ball, 1977), hasta alcanzar la altura convenida para la nueva plataforma, aquella sobre la cual reposarían las torres y cuartos del postrer Edificio II. Los antiguos muros de la Estructura II -sub fueron en parte desmonta. dos por debajo del arranque de una posible bóveda, y lo que aún quedaba expuesto de la crujía posterior fue rellenado con piedra. La nueva construcción que adquirió entonces una clara identidad Río Bec, se incorporó, dejándola despejada, una de las crujías de la antigua estructura ahora provista de una muy baja techumbre perecedera. Su ingreso, una vez bloqueado el acceso original, se practicaría desde lo alto bajando por el techo que era continuación del piso en la reciente plataforma.

En 1933 K. Ruppert observó por primera vez el ancho mascarón frontal del edificio de los años Chintok (figuras 2 y 3 ), entonces en un mejor estado ( $c f$. K. Ruppert y J. Denison Jr., 1943), y antes de finalizar 1977 Agustín Peña concluía la consolidación en la parte alta del enorme mascarón (figura 4). Un texto simbólico al que, si consideramos la cultura como la memoria longeva de la colectividad y si entendemos la memoria como la capacidad que poseen ciertos sistemas de conservar y acumular información, podremos acercarnos con una perspectiva que intente descubrir una comunicación determinada.

La iconografía de un pueblo desaparecido carente de escritura es lo más cercano a los procesos de su pensamiento. Tras la conceptualización de lo representado se encuentra la estructura formal de un pensamiento colectivo, una lógica propia de contenidos o significados donde lo religioso concede un orden a la realidad visible.

Aunque los signos icónicos distan de ser convenciones donde la figuración y el contenido no se encuentran ligados por una motivación interna, es decir, signos convencionales, son sin embargo signos para los que se establecen reglas de equivalencia entre la imagen y el objeto que la motiva, por lo que se ajustan a un código de representación iconográfica ( $c f$. Y. M. Lotman, 1979a) que determina el contenido del signo, esto es, su semántica.

Junto con los signos icónicos, segmentos condensados de la memoria longeva de un grupo, suponemos recuperables fragmentos del esquema 


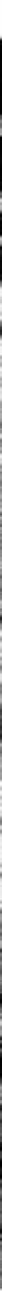

Figura 1. Edificio II y (abajo) Estructura II-sub de Hormiguero, Campeche. 

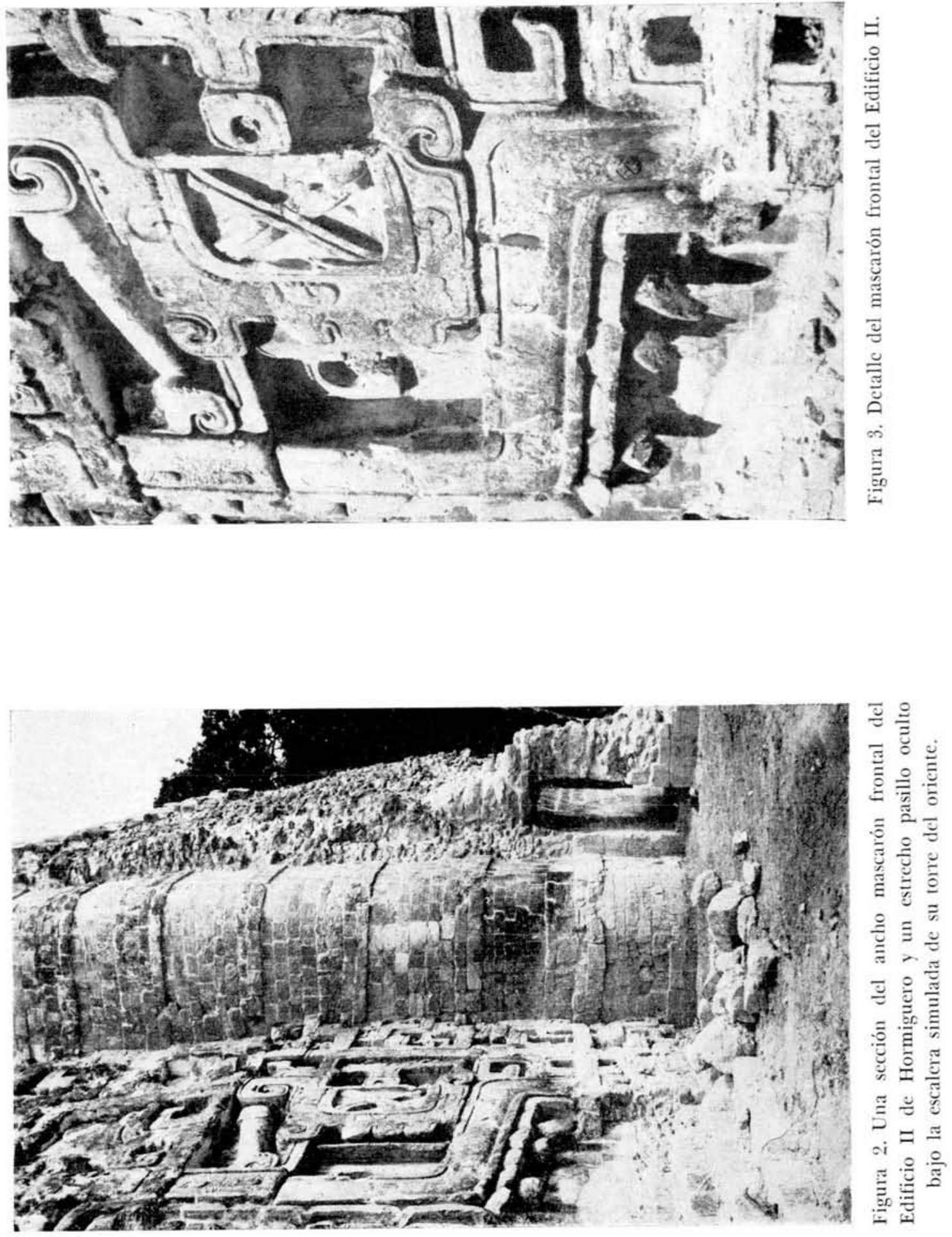


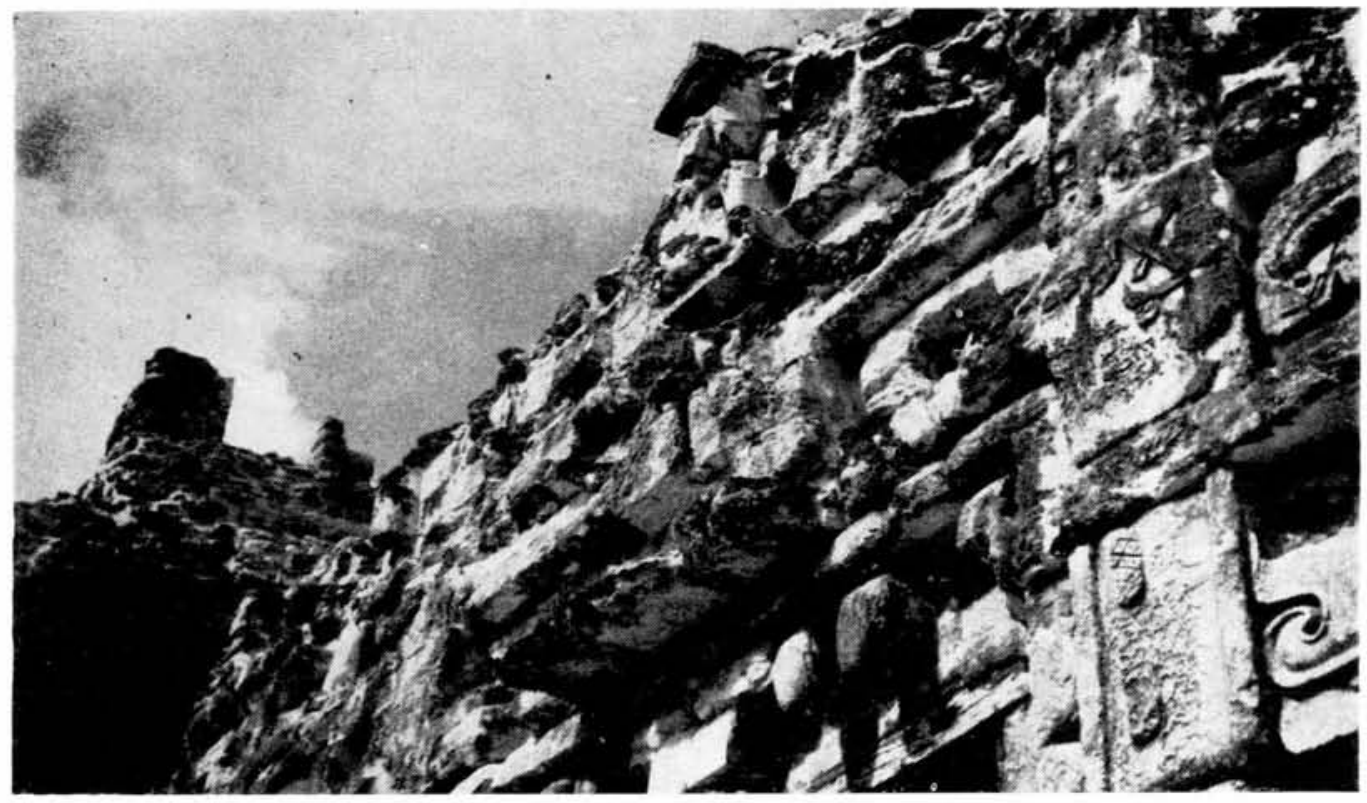

Figura 4. En lo alto de la fachada del Edificio II de Hormiguero fue colocada la figura sedente de un hombre cuyo rostro quedó oculto bajo el signo de una cruz.

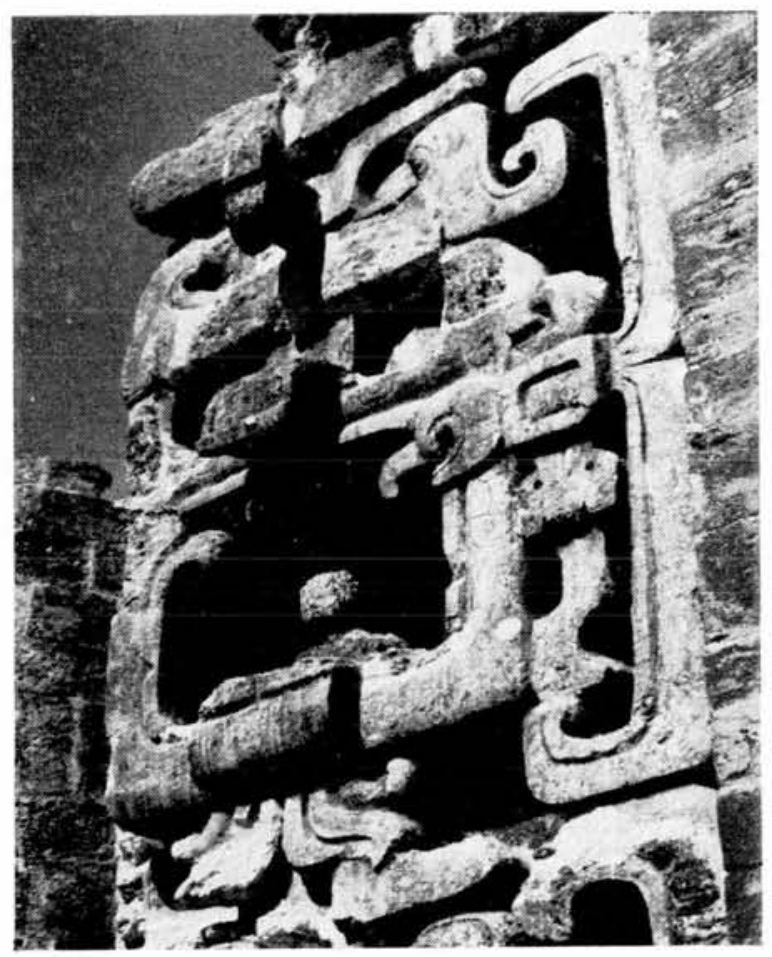

Figura 5. Panel este en el ala poniente del Edificio II. 
DOI: http://dx.doi.org/10.22201/iie.18703062e.1986.55.1276

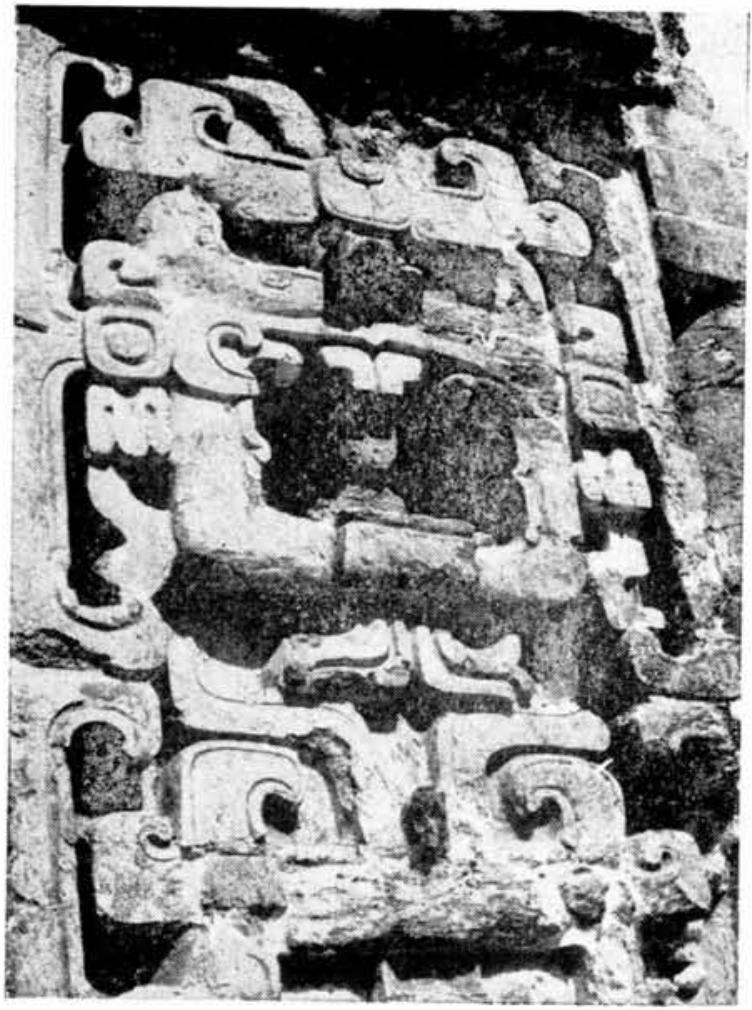

Figura 6. Panel oeste en el ala oriente del Edificio II.

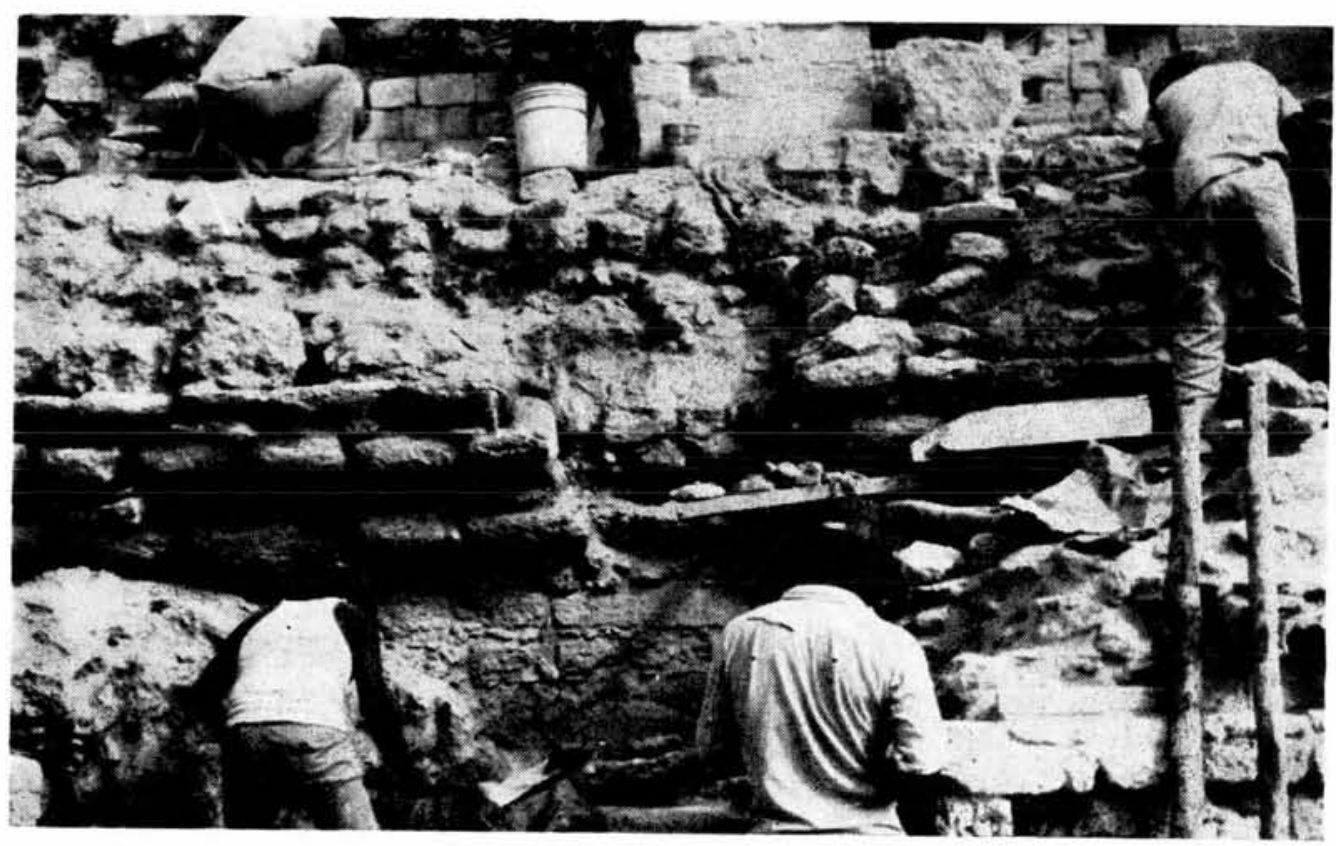

Figura 7. Excavaciones en un cuarto ubicado en la parte baja, ala poniente del Edificio II. 
DOI: http://dx.doi.org/10.22201/iie.18703062e.1986.55.1276

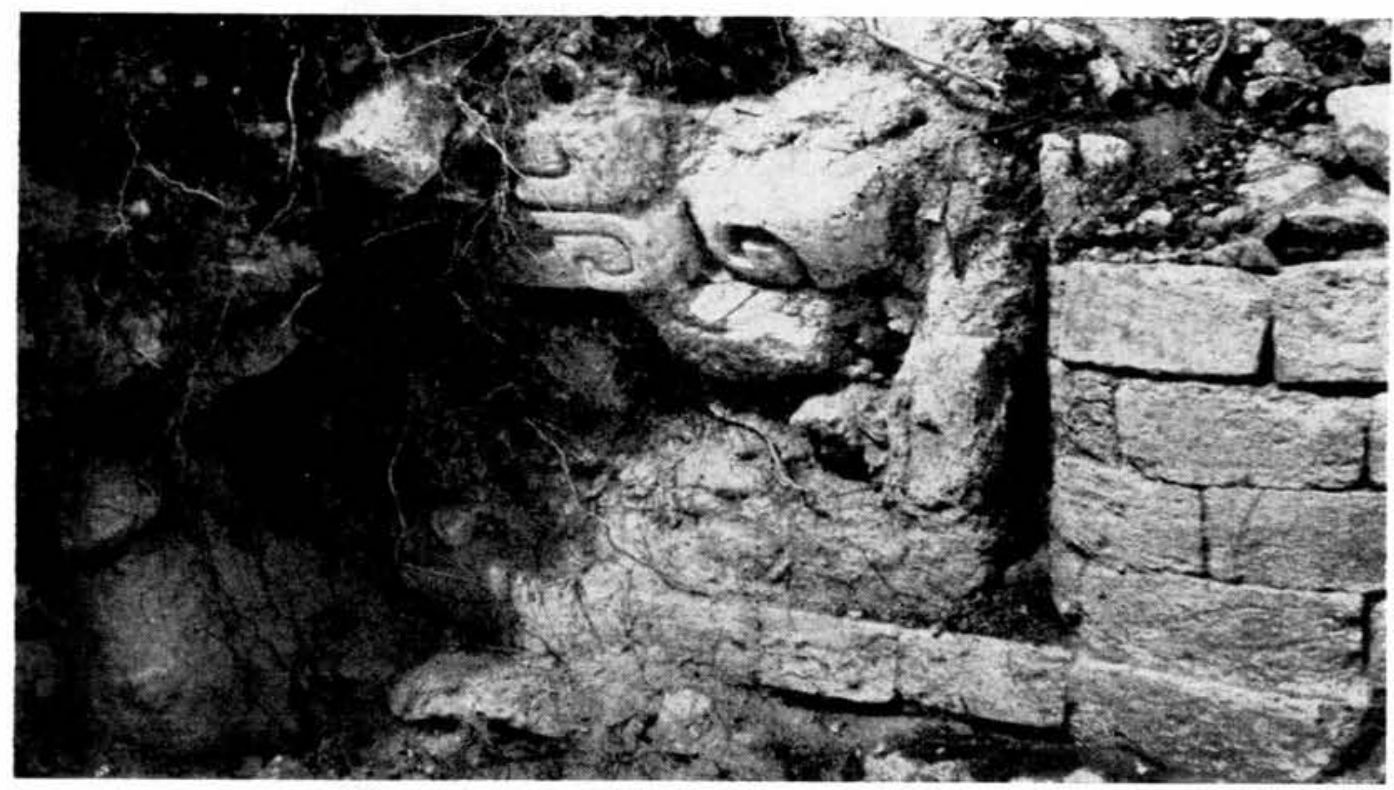

Figura 8. Panel del oeste, en la fachada del mismo cuarto, durante su excavación.

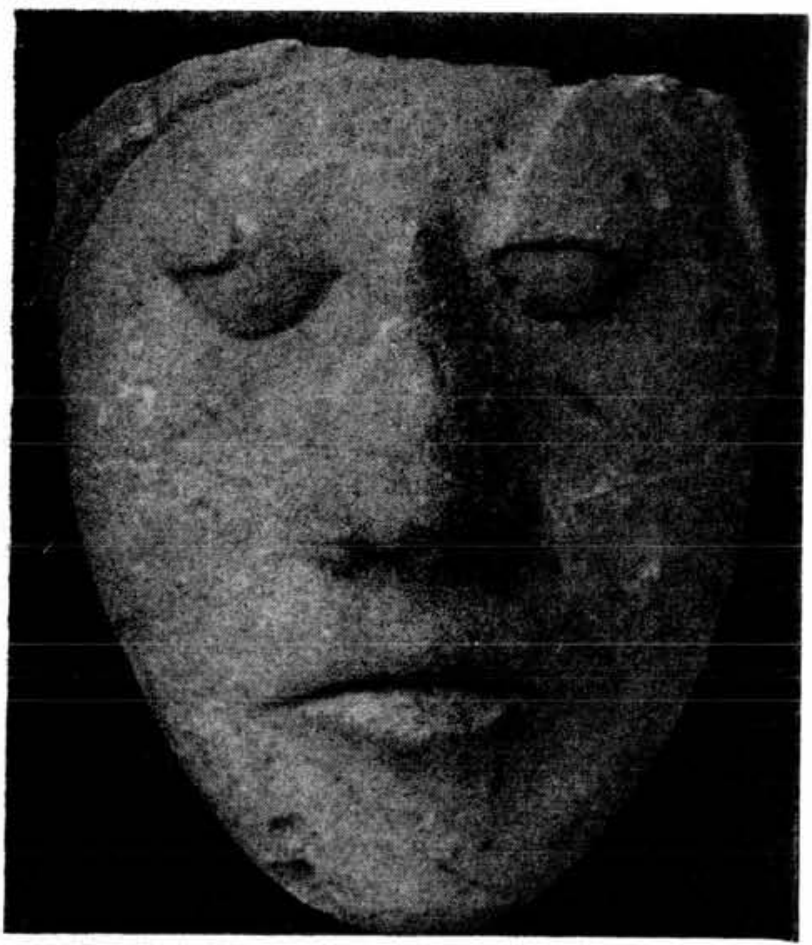

Figura 9. Representación modelada en estuco de un rostro humano. Proviene del Edificio II de Hormiguero, junto al cual se enterró durante la fase Xcocom (ca. 830-970 dC) . 
DOI: http://dx.doioro/1022201/iie_18702062e-1086-55/1276

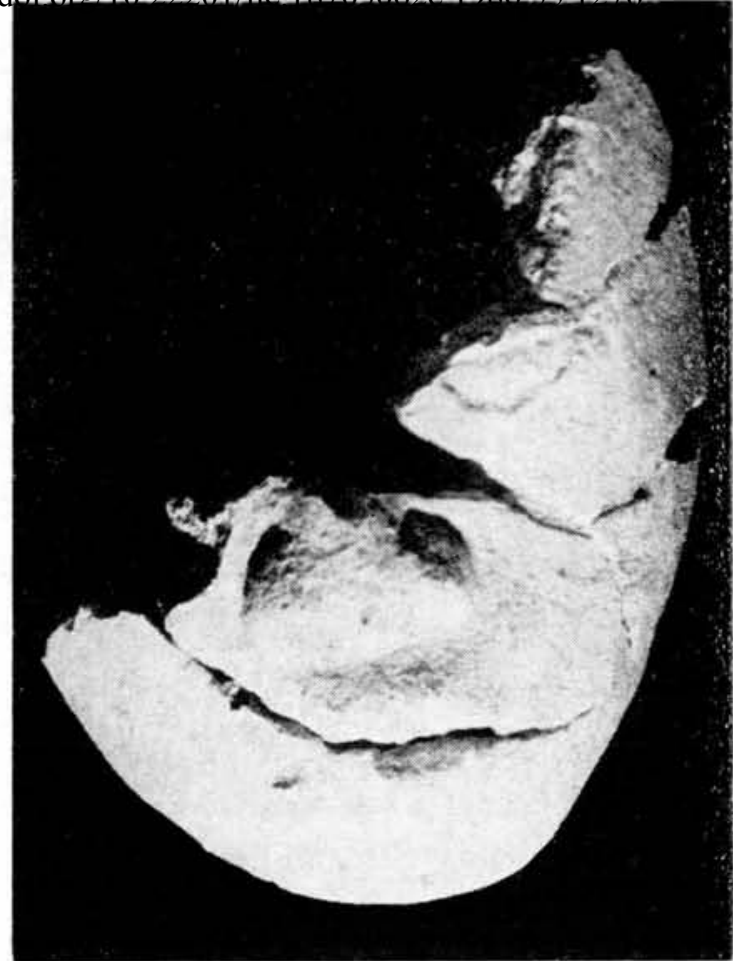

Figura 10. Copia en estuco de la apariencia de us rostro humano. Sus fragmentos se recuperaron a un lado de la cara ilustrada en la figura 9 y al pie del Edificio II de Hormiguero.

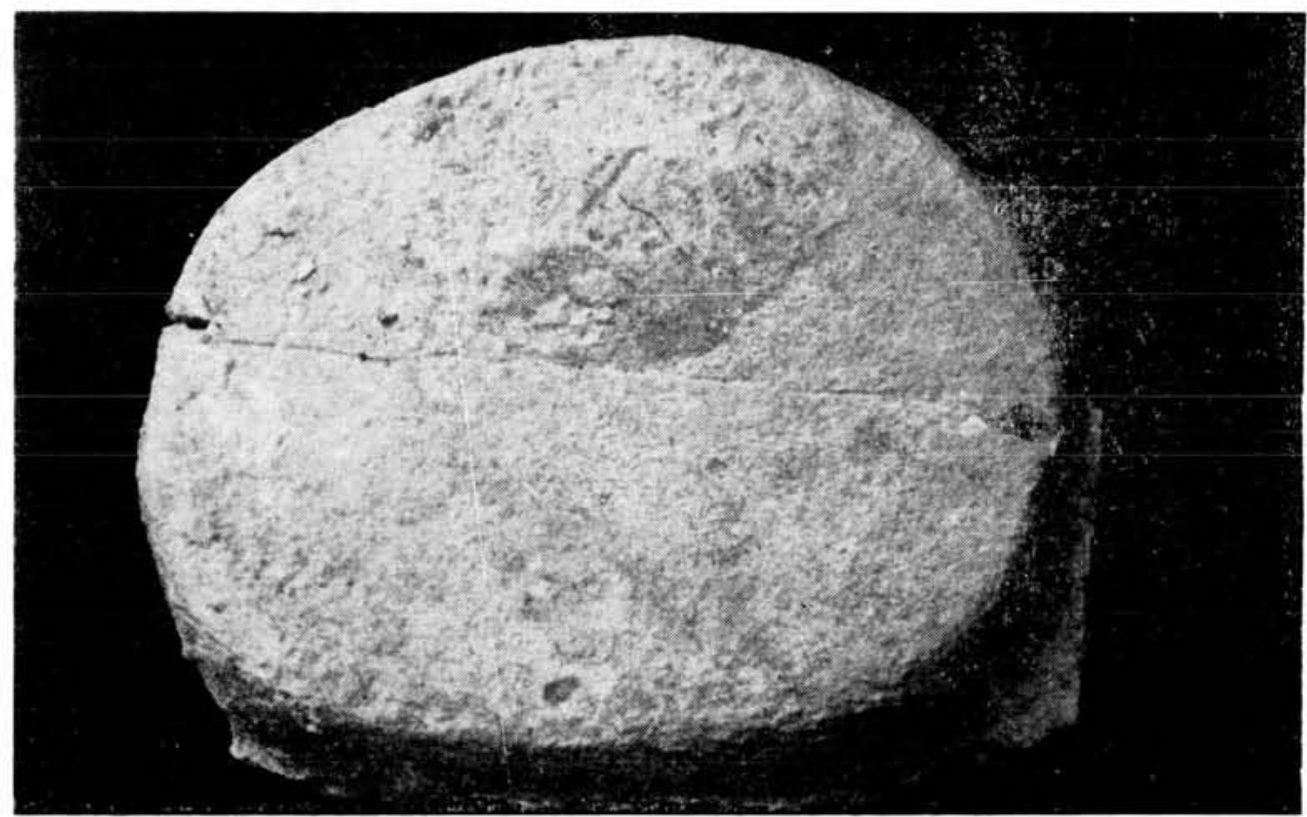

Figura 11. "Paquete" que, modelado en estuco, debió contener un signo pintado. Proviene del Edificio II de Hormiguero. 
de pensamiento de una colectividad desaparecida, partes del propio fenómeno religioso.

Son muchas las dificultades que asisten a la delimitación de los hechos religiosos simples, aquellos que están lo más cerca posible de su origen. El poder indicarlos como tales, diferenciarlos de una actividad no significa, los presupone como parte de una larga evolución histórica que ha desembocado en fenómenos religiosos complejos ( $c f$. M. Eliade, 1972).

Los textos icónicos y el esfuerzo narrativo de un pueblo son componentes de su actual contexto arqueológico. Es una actividad sígnica la recuperable, mas no la simiente del fenómeno religioso. Por tempranos que sean los signos icónicos son en ese entonces producto de una larga evolución conceptual y parte de un fenómeno religioso complejo.

Los iconos simbólicos, es decir, iconos con un valor simbólico asig. nado, si entendemos por símbolo la representación de un concepto asociado a una imagen ( $c f$. Y. M. Lotman, 1979 b), iniciaron su aparición en época muy temprana y desde entonces adquirieron un particular estatuto en el ámbito iconológico propio de la región de Río Bec.

En la búsqueda de una identidad colectiva e imbuidos en una cultura regional, debieron configurarse varias unidades sígnicas. A la conformación de estos signos hubo de preceder un esfuerzo de conceptualización por racionalizar lo cotidiano. El despuntar de lo religioso y el pristino desarrollo conceptual de los grupos que en sus inicios ocu. paron esta parte de la selva desgraciadamente no son accesibles.

Aunque podemos supponer un desarrollo iconográfico previo al de los años Chintok en Hormiguero, fue en ese momento cuando el mascarón frontal del Edificio II debió ser el lugar de encuentro de elementos semióticos independientes asociados por una correlación codificante. Existe, entonces, una función sígnica cuando varios signos, substituciones materiales de un concepto (Y. M. Lotman, 1979 a), revelan una semántica definida por su función en conjunto dentro de una particular relación codificante ( $c f$. U. Eco, 1975).

Los años siguientes, corriendo ya la fase Xcocom, pusieron de manifiesto en Hormiguero una secuencia de sucesos, en apariencia vinculados con una intromisión de grupos originarios del Puuc y portadores de las cerámicas de tipo Pizarra ( $c f . J$. Ball, 1977), que habrían de ocasionar la interrupción del desarrollo cultural Río Bec conocido hasta entonces.

En los últimos días del pasado mes de noviembre, excavando frente 
a uno de los cuartos de reciente aparición en el Edificio II (cuarto q), ubicado en la parte baja de su ala del poniente (figura 7), topamos, al dejar al descubierto el panel oeste en la fachada del mismo cuarto (figura 8), con una multitud de fragmentos de estuco modelado que penetraba bajo la superficie de la plaza. De entre ellos recuperamos dos representaciones de rostros humanos (figuras 9 y 10 ), uno de los cuales (figura 9) enterrado con la intención de que la parte baja de la cara lo mantuviera erguido sobre la tierra, miraba al noreste.

Toda aquella pedacería, que en otro tiempo debió encontrarse anclada en la superficie de algún muro, conforma en la actualidad un contexto arqueológico secundario producto de un antiguo traslado y entierro del material.

A corta distancia de Hormiguero, en Okolhuitz, una de tantas comunidades Río Bec, han sido recuperados algunos estucos modelados a imitación de rostros humanos y en Becán, de entre los escombros del Edificio IV, se obtuvo el cuerpo sedente de un hombre (cf. P. Gendrop, 1983: figura 36).

Sin embargo fue la excavación del Edificio II de Hormiguero aquella que ofreció datos sobre una posible descontextualización intencional de elementos icónicos cuyo cambio de sede, hoy atestiguado por el referido contexto arqueológico de tipo secundario, derivó en la desfuncionalización del conjunto de enunciados que conformaban. Estos elementos sígnicos, hoy fragmentado estuco, debieron interactuar en un texto concreto.

En lo alto de la fachada del edificio de los años Chintok fue colocada la figura sedente de un hombre cuyo rostro habría de ocultarse bajo el signo de una cruz, repentina prolongación de su enorme tocado (figura 4). Arriba, sobre su cabeza, debió encontrar apoyo otro personaje cuya presencia tan sólo queda señalada por el lugar que le sirviera de asiento.

Si bien la restitución de aquel antiguo texto resulta una labor casi impracticable, algunos de sus elementos icónicos - hoy pedacería de estuco esparcida sobre la plaza del Edificio II- debieron copiar o retratar la apariencia de dos personas (figuras 9 y 10 ) en otro tiempo en posición sedente, mientras que un grupo de signos pintados sobre paquetes modelados en estuco (figura 11) quizá enunciaron cl vínculo que aquellos mantenían con Hormiguero. Pocos años des. pués la fachada se habría de encontrar desprovista de algunos de sus 
iconos, las copias de dos hombres habían quedado simbólicamente sepultadas al pie del edificio de los años Chintok.

Los ennegrecidos muros del Edificio II, cuyas manchas se inician bajo el nivel de derrumbe de las bóvedas y, en algún caso, sobre las irregulares superficies dejadas por tal evento, señalan, con algunas cerámicas vinculadas con el quehacer doméstico, la presencia de fogones de los años Xcocom en sus crujías centrales. Entre tanto, los leños de un fogón ardían en otro olvidado edificio. 


\section{BIBLIOGRAFIA}

BaLl, Joseph W.

1977 "The Archaelogical Ceramics of Becan, Campeche, Mexico", en Program of Research in Campeche, National Geographic Society-Tuiane University, Middle American Research Institute, Publiction 43, New Orleans.

Eco, Umberto

1975 Trattato di semiotica generale. Studi Bompiani, 10, Bompiani, Milano.

Eitade, Mircea

1972 Tratado de historia de las religiones. Ediciones Fra, México.

GENDRoP, Paul

1983 Los estilos Rio Bec, Chenes y Puuc en la arquiteclura maya. División de Estudios de Posgrado de Ia Facultad de Arquitectura, UNAM, México.

LoIMAN, Yuri M.

1979a Estética y semiótica del cine "Punto y línea, Gustavo Gili, Barcelona. $1979 b$ "El problema del signo y del sistema sígnico en la tipología de la cultura anterior al siglo xx", en Semiótica de la cultura, Cátedra, Madrid.

Messenger, Lewis C., jr..

1975 Project Becan, 1974: Results of Archaeological Activity in the Rio Bec Region. Tesis de maestría, Universidad de las Américas, Cholula.

Ruppert, Karl y John Denison, jr.

1943 Archaeological Reconnaissance in Campeche, Quintana Roo and Peten. Carnegie Institution of Washington, Publication 543. 